\title{
Keto-Enol Driven Assembly of Methyl Pyruvate on Pt(111)
}

\author{
S. Lavoie, M-A. Laliberté, G. Mahieu, V. Demers-Carpentier and P. McBreen.
}

\section{RAIRS spectra:}

Spectrum A in Figure 2 of the paper displays a carbonyl band at $1735 \mathrm{~cm}^{-1}, v(\mathrm{C}-\mathrm{O})$ bands characteristic of the $\mathrm{OCOCH}_{3}$ moiety of methyl pyruvate in the $1300-1200 \mathrm{~cm}^{-1}$ region and a $\mathrm{CH}_{3}$ deformation band at $1447 \mathrm{~cm}^{-1}$. The additional bands at 1594 and $1367 \mathrm{~cm}^{-1}$ are attributed to the enol tautomer. Spectrum (A) was recorded for approximately full monolayer coverage.

Calculated frequencies for the (mixed) $v(\mathrm{C}=\mathrm{C})$ vibration of enol tautomers of pyruvic acid were in the range 1634-1670 $\mathrm{cm}^{-1}$. (Raczynska, E. D.; Duczmal, K.; Darowska, M. Vib. Spectrosc. 2005, 39, 37.)

The enol tautomer of phenylpyruvic acid displays a $v(\mathrm{C}=\mathrm{C})$ band at $1657 \mathrm{~cm}^{-1}$. (Hanai, K.; Kuwae, A.; Kawai, S.; Oko, Y. J. Phys. Chem. 1989, 93, 6013).

Bands at 1618 and $1627 \mathrm{~cm}^{-1}$ were assigned to the $v(\mathrm{C}=\mathrm{C})+v(\mathrm{C}=\mathrm{O})+\delta(\mathrm{OH})$ vibration of benzoylacetone (a) and dibenzoylmethane (b) enols, respectively.

(a) Tayyari, S. F.; Emampour, J. S.; Vakili, M.; Nekoei, A. R.; Eshghi, H.; Salemi, S.; Hassanpour, J. Mol. Struct. 2006, 794, 204.

(b) Hansen, B. K. V.; Winther, M.; Spanget-Larsen, J. J. Mol. Struct. 2006, 790, 74.

A band at $1574 \mathrm{~cm}^{-1}$ was assigned to the $v(C=C)+v(C-O)$ stretching vibration of $\eta^{1}$-acetone enolate on Ni(111). ( Sim. W,-S.; Li, T.-C.; Yang, P.-X.; Yeo, B.-S. J. Am. Chem. Soc. 2002, 124, 4970). 


\section{Keto-Enol Driven Assembly of Methyl Pyruvate on Pt(111)}

S. Lavoie, M-A. Laliberté, G. Mahieu, V. Demers-Carpentier and P. McBreen.

\section{Figure S.I 1.}

STM images of methyl pyruvate (MP) on $\mathrm{Pt}(111)$. (A) MP on clean $\mathrm{Pt}(111)$ at room temperature. (B) MP on exposure to clean $\mathrm{Pt}(111)$ at $150 \mathrm{~K}$. (C) MP at room temperature on $\mathrm{Pt}(111)$ in the presence of a background pressure of $\sim 10^{-6}$ Torr $\mathrm{H}_{2}$.

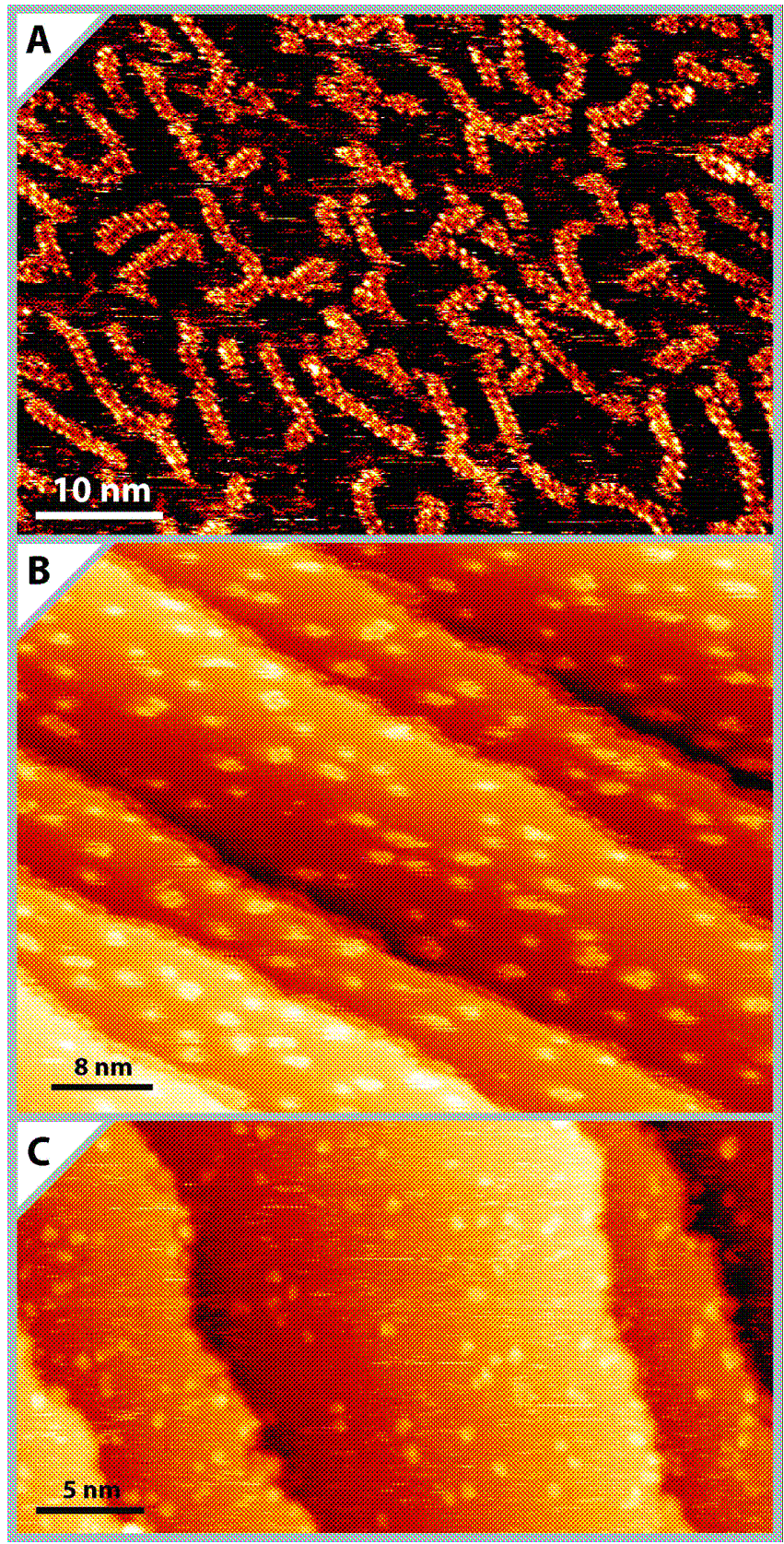

Fig. S.I. 1 